\title{
Envelhecimento ativo: proveniências e modulação da subjetividade
}

\author{
Active aging: origins and modulation of \\ subjectivity \\ Envejecimiento activo: las fuentes y la modulación \\ de la subjetividad
}

Silvana Tótora

RESUMO: Propõe-se problematizar o enunciado coletivo de envelhecimento ativo tomando como referência o Programa OPAS-OMS (2005) e seus desdobramentos no Relatório de 2015. Utilizo Foucault e sua analítica dos mecanismos de poder. Destaco a proveniência dos enunciados de envelhecimento ativo. Retomo desse filósofo o conceito de capital humano. Por fim, enfatizo a construção de um modo de subjetivação com base na ética como estética da existência, a fim de promover um deslocamento do termo ativo, anexado ao envelhecimento, para artista.

Palavras-chave: Envelhecimento Ativo; Subjetividade; Foucault.

ABSTRACT: This article discusses the collective statement of active aging, taking as reference the PAHO-WHO Program (2005) and its unfolding in the 2015 Report. I use Foucault and his analysis of the mechanisms of power. I highlight the origins of the statements of active aging. I use from this philosopher the concept of human capital. Finally, I emphasize the construction of a subjectivation mode based on ethics as the aesthetic of existence, in order to promote a shift from the active term attached to aging, to artist.

Keywords: Active Aging; Subjectivity; Foucault. 
RESUMEN: En este artículo se analiza la declaración colectiva del envejecimiento activo tomando como referencia el Programa OPS-OMS (2005) y su desarrollo en el Informe 2015. Utilizo Foucault y su análisis de los mecanismos del poder. Destaco los orígenes de las afirmaciones del envejecimiento activo. Yo uso de este filósofo el concepto de capital humano. Finalmente, enfatizo la construcción de un modo de subjetivación basado en la ética como estética de la existencia, para promover un cambio del término activo ligado al envejecimiento, al artista.

Palabras llave: Envejecimiento activo; Subjetividad; Foucault.

\section{O governo das velhices}

A Organização Mundial de Saúde (OMS), ao renomear o Programa de Saúde do Idoso como Envelhecimento e Saúde, em 1995, deslocou a abordagem da velhice circunscrita a um momento específico da vida de indivíduos ou da população para um processo contínuo de desenvolvimento ao longo da vida. Daí o emprego de curso de vida em lugar da compartimentalização por faixas etárias (OPAS-OMS, 2005, p. 54).

O Programa da OMS, com metas de alcance global, regional e local, estimula as iniciativas intersetoriais e interdisciplinares, particularmente, aquelas dos países em desenvolvimento. Todos - governo, iniciativas privadas, organizações não governamentais, comunidades e, principalmente, a população - doravante, devem se comprometer com o futuro das gerações, garantindo uma vida saudável. A velhice se apresenta como o futuro de todos. Eis as bases para a construção de um consenso que envolverá, sem distinção, governantes e governados, na grande cruzada mundial em favor do envelhecimento ativo. Afinal, queremos ou não uma vida longa, ativa e saudável? Essa é a aposta no sucesso do Programa.

O envelhecimento ativo configurou-se na palavra de ordem do novo milênio ${ }^{1}$. Há mais de uma década esse novo conceito modula as subjetividades, mobiliza a comunidade científica - multiplicam-se as pesquisas nas áreas da gerontologia e geriatria - e, principalmente, ganha ampla difusão e popularização através das mídias.

Afinal, o que se entende por envelhecimento ativo?

\footnotetext{
1 No Ano Internacional do Idoso (1999) foi lançado, no Dia Mundial da Saúde, o movimento global pelo envelhecimento ativo (OMS-OPAS, 2005, p. 55).
} 
Esse conceito, de acordo com o Programa da OPAS-OMS (2005, p. 13), compreende "um processo de otimização das oportunidades de saúde, participação e segurança, com o objetivo de melhorar a qualidade de vida à medida que as pessoas ficam velhas". E ativo não se restringe aos aspectos físicos ou à força de trabalho, mas à "participação contínua nas questões sociais, econômicas, culturais, espirituais e civis" (OPAS-OMS, 2005, p. 13).

Velhos (as) e jovens são convocados à participação contínua, alçados à condição de cidadãos portadores de direitos, registrados em estatutos específicos e promulgados em leis ${ }^{2}$. As velhices, especialmente, são chamadas à responsabilidade nos processos políticos de sua comunidade (familiar, vizinhança, religiosa etc.) e, principalmente, por sua saúde. Com isso, espera-se constituir uma nova cultura que daria visibilidade e status positivo à velhice, além de envolvê-la no compromisso com as futuras gerações. Enfim, o tempo da velhice não seria somente o passado, suas lembranças e memória, mas essa promessa de futuro.

Todos e cada um são enlaçados na trama do tempo linear, ligados ao movimento em direção ao futuro e, ao mesmo tempo, à linha horizontal do curso do tempo que vai do antigo presente (passado) ao atual. Englobados nesse horizonte temporal, as velhices "bemsucedidas" deverão transmitir aos jovens e adultos a crença no estilo saudável de vida (prevenção e promoção da saúde) como o caminho para viver mais e melhor.

Mesmo ciente do declínio da capacidade funcional nas idades mais avançadas, a população em geral alimenta a expectativa de atingir a velhice desfrutando da qualidade de vida. E essa implica na manutenção da autonomia e independência, ambos de abrangência restrita. O primeiro refere-se à possibilidade de escolha de acordo com suas próprias regras, e o segundo diz respeito à manutenção da habilidade na execução de funções relacionadas à vida diária (OPAS-OMS, 2005, p. 13). No entanto, "não são os possíveis que são submetidos a nossa escolha; pelo contrário, é nossa potência de escolher que é submetida a possíveis preestabelecidas" (Lapoujade, 2015, p. 263). Assim como a independência não diz respeito à sujeição ao governo das condutas pelo marketing dos valores de uma sociedade de mercado.

Diversidade, autonomia e independência são conceitos de alcance limitados quando situados no âmbito de uma política de envelhecimento ativo que não coloca em questão o funcionamento da máquina capitalista e os dispositivos de poder de subjetivação.

\footnotetext{
${ }^{2}$ O Estatuto da Pessoa Idosa foi promulgado pela Lei Federal n. ${ }^{\circ} 10.741$, de 01 de outubro de 2003.
} 
A amplitude que se pretende dar ao termo ativo compreende a tríade saúde, segurança, e participação, detalhadas em objetivos, ações, e metas que constituirão uma plataforma para uma construção consensual e abrangente de diferentes setores e regiões. Resta, portanto, pouco ou quase nenhum espaço para o dissenso, as singularidades e as diferenças - no sentido de uma individuação que transvalora os valores difundidos. Aliás, esses termos não são utilizados no Programa.

Cada uma das três ações — saúde, participação e segurança — são detalhadas e esmiuçadas em objetivos, metas e ações específicas (OPAS-OMS, 2005, pp. 46-53). Em linhas gerais, compreende-se por saúde uma ação que mantenha num patamar baixo os riscos (comportamentais e ambientais) de desenvolvimento de doenças crônicas e de declínio funcional, e, por sua vez, um patamar elevado os fatores de proteção que permitam às pessoas desfrutarem de maior quantidade e qualidade de vida (OPAS-OMS, 2005, p. 45).

A participação diz respeito ao amplo compromisso de diferentes setores sociais em assegurar que aqueles que envelhecem ou estão na velhice tomem parte ativa do mercado de trabalho formal, informal e voluntário; e apoiar sua participação nas atividades sociais, econômicas, culturais e espirituais segundo suas preferências, condições, e com respeito aos direitos humanos fundamentais (OPAS-OMS, 2005).

A segurança envolve a garantia e o apoio aos programas e políticas de defesa dos direitos dos idosos à segurança social, financeira e física, assistindo àqueles que não podem manter-se, seja individualmente, seja por meio da ajuda aos seus familiares. Essa formulação pode ser lida como um mecanismo compensatório. Isto porque, na medida em que os problemas, na atualidade, advindos de um mercado de empresa concorrencial, em que vigora a competitividade e a desigualdade, não são questionados, sequer tocados, ao contrário, reforçados de modo ativo, os direitos de seguridade à velhice, particularmente aos mais pobres, soa como compensação pelos efeitos indesejáveis desse sistema econômico. Assim, o Programa indica aos governos uma ajuda financeira para aqueles indivíduos ou familiares que não possuem renda suficiente. Ora, não seria esta uma maneira, de os governos, garantirem certo nível de consumo?

Importa, contudo, destacar significativas mudanças de abordagem, estabelecimento de metas e alvos das políticas sociais expostas no Programa do Envelhecimento Ativo (OPAS-OMS, 2005): primeiro, e mais importante, a reafirmação da Assembleia Mundial, em 2002, da colocação do envelhecimento populacional na agenda política, traduzido como a celebração dos "triunfos de um mundo em processo de envelhecimento" (OPAS-OMS, 2005, p. 55); 
segundo, a produção de políticas de alcance global, cabendo aos governos dos países, regiões e localidades a sua implantação; terceiro, o deslocamento e a ampliação do alvo, da saúde física e mental da população de indivíduos, restritos a sua dimensão biológica ou psicológica, para seus aspectos ambientais (moradia, ambiente físico, qualidade do ar e da água, clima etc.); quarto, a inclusão dos aspectos transversais da cultura e de gênero; quinto, a colaboração na implementação do Programa entre as agências internacionais, organizações governamentais e não governamentais e os setores acadêmicos, com amplo sistema de difusão e popularização através das mídias; sexto, o protagonismo ou responsabilidade pessoal e da população pelo sucesso do Programa, exigindo a participação contínua da cidadania portadora de direitos. Esses dois últimos itens dizem respeito ao novo conceito de governança global, ou a partilha de decisões e ações.

Diante desses relatos iniciais, gostaria de situar o problema que orienta a construção desse texto. Diferentemente de um engajamento na difusão desse Programa de Envelhecimento Ativo, tampouco do desenvolvimento de pesquisas para subsidiá-lo, escolho outro percurso que problematiza os programas dessa natureza e, particularmente, os caminhos adotados nessa nova abordagem para o envelhecimento e a velhice.

A problemática que orienta a construção desse artigo é de natureza minoritária. Por minoria entendo aqueles que deixam de satisfazer um ou outro requisito do Programa e são colocadas fora do sistema. Minoritário não diz respeito apenas a grupos ou classes, mas, em cada um de nós, a potencialidades que não são mantidas em razão das submissões de nossas potências às exigências dos modelos de vida adotados pela maioria. Proponho um novo campo de problematização com base na ética entendida como práticas de si (cuidado de si) ou potências minoritárias, pondo em jogo os critérios de uma estética da existência. Na companhia de Foucault (2004), entendo essas práticas como modos singulares e coletivos de resistência às tecnologias de governo das condutas de cada um e de todos.

Indica o filósofo (Foucault, 2004, pp. 306-307) um campo estratégico de poder no sentido mais amplo do que as relações políticas institucionais. Essa última refere-se a uma concepção jurídica do sujeito de direito, enquanto a primeira aponta para uma análise reversível, móvel e transformável das relações de poder de si para consigo constituindo-se uma ética do sujeito. Nesse último sentido podemos abrir uma nova perspectiva de um envelhecimento artista, como um percurso singular que não se deixa capturar em Programa, como o do envelhecimento ativo. Proponho situar a análise nos mecanismos de poder que atravessam esse Programa referido. 
E, com base em Foucault, situar esse Programa como a emergência de um novo regime de verdade que visa à modulação das velhices. Assim posto, também o fracasso das metas compõe a estratégia de ampliação das adesões. O percurso adotado, portanto, passa ao largo de uma metodologia de análise que insiste em traçar contradições e polaridades entre a proposta e a realidade, pois o Programa, por si mesmo, institui sua própria realidade e seu sujeito-alvo. Haja vista o traçado inicial da velhice sob a ótica do envelhecimento populacional e a prospecção do seu crescimento. Como população, as velhices tornam-se um problema de governo que, doravante, deverá considerar o seu processo de envelhecimento.

A emergência da velhice como problema populacional no final do século XX não seria somente a reedição dos dispositivos de poder vigentes desde o século XIX, e denominados por Foucault (2005) de biopolítica, cujo alvo era fazer viver ou prolongar a vida biológica da espécie humana. Trata-se, agora, de um controle contínuo do curso da vida, tanto biológica quanto ambiental, num jogo de relações variáveis que favoreçam a “obtenção da melhor qualidade de vida possível e para o maior número de pessoas possível" (OPAS-OMS, 2005, p. 54).

Nota-se o surgimento de um novo dispositivo de poder que Deleuze (1992) descreveu como "sociedade de controle", e Passetti (2013) denominou de ecopolítica.

Segundo esse autor, a ecopolítica seria uma prática de governo planetária que se apoia na produção de verdade de um capitalismo sustentável que estabelece as seguintes metas: combater a pobreza, elevar os indicadores econômicos, auferir índices de felicidade e desenvolvimento humano, tais como saúde, educação e cultura; disseminar uma cultura da paz; educar as pessoas para a resiliência ${ }^{3}$, encontrar certa qualidade de vida com redutores de vulnerabilidades, gerar condições compartilhadas para uma vida melhor, de pessoas, ares, mares e florestas; ocupar inteligências por meio de participações, conexões e afirmação de direitos, segurança, securitização; em suma, trata-se do governo não somente da vida nos seus aspectos biológicos, mas de tudo que se mostre vivo no presente para um futuro melhor (Passetti, 2013, pp. 10-12). Essas metas deverão ser assumidas pelos governos dos Estados — em âmbito, nacional, regional e local.

\footnotetext{
${ }^{3}$ Acerca da resiliência, cf. Oliveira (2012). Esse conceito foi cunhado pela física para aferir a suportabilidade de um material diante de um impacto. Transferido para as populações humanas, esse termo vem sendo utilizado no sentido contrário às resistências, para prover adaptações mais próximas a adequações. A resiliência "permite que uma pessoa, grupo ou comunidade previna, minimize ou supere os efeitos nocivos das adversidades" (Oliveira, 2012, p. 113).
} 
O emprego do termo qualidade de vida no Programa do Envelhecimento Ativo (OPAS-OMS, 2005) contempla a dimensão biológica e ambiental, e o conceito de envelhecimento ativo modula uma subjetividade responsável e participativa.

Almeja-se, com isso, harmonizar as relações entre governantes e governados, tornando os governados corresponsáveis pela gestão e sucesso das políticas. Aliás, o capitalismo sustentável governamentaliza ${ }^{4}$ o Estado e almeja envolver toda uma população num projeto comum, contendo as resistências e pacificando os conflitos gerados pelas desigualdades de poder, riqueza e acesso aos benefícios públicos.

No Relatório Mundial de Envelhecimento e Saúde (OMS, 2015), o conceito de envelhecimento saudável ganha centralidade com base no novo conceito de capacidade funcional. A medição ou promoção da saúde na população de "adultos maiores", com impacto sobre o seu bem-estar, segundo esse relatório, poderá realizar-se por meio da capacidade funcional que combina dois elementos: o primeiro de natureza intrínseca, referente à capacidade física e mental em que cada indivíduo pode se apoiar em qualquer ponto no tempo; segundo, o ambiente em que vive. A combinação e a interação entre ambos os elementos, individuais e ambientes favoráveis, configuram-se na capacidade funcional. Assim, o Relatório define "o envelhecimento saudável como o processo de desenvolvimento e manutenção da capacidade funcional que permite o bem-estar em idade avançada" (OMS, 2015, p. 13). E, nos fins do Relatório, a otimização da capacidade funcional constitui o objetivo comum da Saúde Pública para o envelhecimento saudável. O termo saudável vem ocupar o lugar do ativo, empregado no Relatório de 2005.

Com base em Foucault, referindo-nos à sua analítica dos dispositivos de poder e de sua proveniência, destaco os baixos começos dos enunciados de envelhecimento ativo e da capacidade funcional que integram a definição de envelhecimento saudável. Retomo desse filósofo a análise do neoliberalismo da Escola de Chicago, por meio da teoria do capital humano, cunhada por Teodore Schultz e Gary Backer - eminentes professores universitários ganhadores do Nobel de Economia - com publicações separadas no início da década de 1970 (Foucault, 2008b, p. 304).

Esses neoliberais retomam uma definição de economia como análise do comportamento humano, de sua racionalidade e a estratégia dos indivíduos.

\footnotetext{
${ }^{4}$ Foucault empregou pela primeira vez o termo governamentalidade no curso de 1978, Segurança, Território e População, para designar o governo das condutas dirigido à população com os recursos da economia política e dos dispositivos de segurança (Foucault, 2008a). A governamentalização do Estado compreende "o governo dos vivos", que Foucault (2014, p. 112) emprega "num sentido amplo como um conjunto de técnicas e procedimentos destinados a dirigir a conduta dos homens".
} 
Nessa direção, propõem estudar "o trabalho como conduta econômica praticada, aplicada, racionalizada, calculada por quem trabalha" (Foucault, 2008b, p. 307).

Sob essa perspectiva, deixam de abordar o trabalhador como força de trabalho captável no mercado de oferta e procura fazer dele um sujeito ativo (Foucault, 2008b, p. 308).

Sob a referência do trabalho, cada trabalhador seria uma máquina, no sentido positivo, que produziria fluxos de renda distintos no curso da vida: baixa quando jovem, alta na fase adulta, e reduzida na velhice. Essa escala se mede pela relação capitalcompetência, e cada trabalhador seria um empresário de si mesmo. Desse modo, a sociedade se constituiria de unidades empresas (Foucault, 2008b, p. 310).

Esse trabalhador como empresário de si mesmo produz sua própria renda que, segundo G. Becker (citado em Foucault, 2008b, p. 311), resulta na sua satisfação. A renda gerada pelo trabalho depende dos recursos inatos ou adquiridos que compõem o capital humano. Os primeiros são os equipamentos genéticos recebidos de seus ascendentes e que podem diminuir ou aumentar os riscos de contrair doenças ao longo da vida. Já os adquiridos referem-se aos investimentos educacionais, não necessariamente numa profissão, mas no equilíbrio do ambiente familiar e nos aspectos da cultura do país. O nível de desenvolvimento pessoal ou de um país está, portanto, vinculado ao investimento na formação desse capital humano.

O exercício do governo está fortemente apoiado numa intervenção ativa com base na Lei. Ambos visam a assegurar um ambiente favorável à livre criação desse capital humano ou indivíduo-empresa ou empreendedor - termo popularizado e empregado na atualidade. Essa teoria da Escola de Chicago espraia-se como regime de verdade para todos os comportamentos sociais e governo das condutas, os quais se orientam por uma economia de mercado.

Assim, os cuidados médicos, a higiene pública e o envelhecimento populacional deverão ser repensados com base na produção desse capital humano.

Podemos situar nesse enfoque a nova visão sobre a velhice imprimida pelo Programa da OMS-OPAS (2005). O deslocamento para o envelhecimento ativo compreende um governo das condutas pelos próprios sujeitos com a intervenção de políticas de governo sobre o "curso da vida", cujo investimento visa a estancar o processo de declínio da capacidade funcional (OMS, 2015) e a ampliação das oportunidades, para todas as idades, de participação ativa na sociedade ou mercado de produção e consumo. 
Dessa forma, a velhice — ou, no termo empregado, a terceira idade — não deve ser vista associada aos valores tidos como negativos, tais como aposentadoria, doença ou dependência. Ao contrário, afirma-se um novo paradigma que "perceba os idosos como participantes ativos de uma sociedade, e beneficiários do desenvolvimento" (OPAS-OMS, 2005, p. 44). Esse novo regime de verdade requer a ampliação das oportunidades, por meio de "programas que apoiem o aprendizado em todas as idades e permitam às pessoas entrar e sair do mercado de trabalho para assumir o papel de cuidadores em diferentes momentos" (OPAS-OMS, 2005, p. 44). Como cuidadores, os idosos tanto exercem o autocuidado, quanto são suportes na família por meio do cuidado dos netos, liberando os filhos para o estudo e/ou trabalho. Aliás, o Relatório Mundial do Envelhecimento e Saúde (OMS, 2015, p. 10) reforça a contribuição das pessoas idosas para a economia, com base em pesquisas realizadas no Reino Unido, em 2011, e, especialmente das mulheres mais velhas, na Zâmbia.

Os idosos, juntamente com a mídia, sugere o Programa da OMS-OPAS (2005), devem constituir-se liderança — hoje, o termo mais usado é o protagonismo - no combate aos estereótipos e em prol do reconhecimento social e político. A educação de jovens na defesa dos direitos das "pessoas mais velhas" também pode favorecer a redução da discriminação e do abuso (OMS-OPAS (2005, p. 44).

Não se trata de contestar a validade dessas indicações, mas inseri-las no contexto de uma sociedade cujos valores e relações que a engendram são aqueles de uma sociedade de mercado em que o sujeito ativo é o empresário de si, capital humano ou empreendedor. Ignorar essa realidade e apregoar a busca de consenso entre governo, empresas, organizações não governamentais e mídia em prol do envelhecimento ativo não seria sujeitar a velhice à servidão dessa máquina social? Faz-se necessário problematizar a velhice e o envelhecimento no contexto atual como produção de uma servidão.

Longe dessa abordagem que reclama o consenso inclusivo através da participação de todas as idades num Programa comum de envelhecimento ativo e de envelhecimento saudável, associo-me aos filósofos Nietzsche, Deleuze, Guattari e Foucault para pensar um percurso singular para o envelhecimento e a velhice, com base na potência e na ética como estética da existência. Trata-se, como já dito, de um envelhecimento artista. 


\section{Governo das condutas e as contracondutas: como a velhice se situa na atualidade?}

Um evento da história recente é a emergência de uma pluralidade de tecnologias de governo que se encarregam da conduta de cada um e da população. Refiro-me, particularmente, no final dos anos 1980, à população dos velhos.

A velhice vem sendo tratada como um fenômeno populacional capturado nas malhas do governo das condutas, incumbido de dirigir a vida nos seus aspectos biológicos e ambientais, tais como: promoção da saúde de cada um e de uma multiplicidade em movimento; criação de um ambiente favorável à denominada qualidade de vida; controle das doenças endêmicas e crônicas.

Todo esse conjunto de dispositivos de governamento não são recursos somente do governo do Estado, mas estão também a cargo de empresas privadas (laboratórios biomédicos, planos privados de saúde, empresas de seguros, mídias, empresas de lazer e promoção da qualidade de vida). O prolongamento da vida (no sentido do tempo cronológico), ou a longevidade, constitui um efeito das tecnologias da biopolítica que, desde o século XIX, encarregou-se da vida na acepção biológica. Uma máquina de fazer viver e deixar morrer, como afirmou Foucault (2005).

Os saberes que resultam dessas tecnologias de poder e as alimentam provêm das áreas biomédicas e daquelas imbuídas de prevenir os males que possam reduzir a passagem cronológica do tempo e de promover a chamada qualidade de vida. Um presente de sujeição justifica-se em razão da contenção do aleatório da existência com a promessa no futuro de uma velhice com qualidade. Também se acoplam os saberes oriundos de uma máquina social tecnológica (a linguagem da informática, signos diretamente ligados à máquina, índices de mercado de ações, capital genético, que não representam um sujeito individuado).

Esses saberes são armazenados em bancos de dados e funcionam como dispositivos do marketing. Os dados são vendidos para milhões que consomem hábitos de vida, alimentação, lazer, saúde e bem-estar, e também a denominada qualidade de vida com vistas ao envelhecimento ativo. Tudo isso não passa de informações "dividuais" cujos "perfis" são resultantes do cruzamento de dados (Deleuze, 1992, p. 222; Lazzarato, 2014, p. $38)$.

\footnotetext{
${ }^{5}$ O termo "divíduo" vem de divisíveis, e foi empregado por Deleuze (1992, p. 222) para se referir à divisão dos indivíduos em "perfis" moduláveis por cruzamento de dados armazenados em "bancos" de dados, pesquisas de mercado ou de opinião.
} 
O envelhecimento ativo é a fabricação de uma subjetividade modulável aos comportamentos tidos como responsáveis por prolongar a vida com qualidade. E somente dessa forma se justifica viver muito. Ativa é a adjetivação da vida que seguiria um curso normal e linear do nascimento à morte.

Vidas conformadas pelo marketing que vende a promessa de um futuro, fazendo das velhices bem-sucedidas a isca para capturar e governar a conduta dos demais viventes.

Podemos entender como ativa a intervenção sobre o fluxo de produção e consumo da subjetividade. As multiplicidades de relações — de forças, de potências e de afetos — que atravessam o corpo de cada um ou de uma coletividade são postas sob a direção de um governo externo. Cada um e todos atrelados à política ativa dos governos de Estado e empresas privadas que dirigem a conduta de cada um e de todos para o mercado de produção e consumo não somente de bens materiais, mas dos imateriais, dentre outros: bem-estar, felicidade, bom humor... E as singularidades são canalizadas no sentido da extração de inteligências úteis para a criação do mercado concorrencial. Velhos(as) e jovens podem igualmente ser considerados ativos, desde que empreendam esforços no investimento sobre si mesmos — aquisição de conhecimentos e habilidades —, sejam bons gestores de sua saúde, empresários de si mesmos e empreendedores.

Em suma, ser ativo é produzir um capital humano que possa ser disputado pelo mercado concorrencial, gerador de uma renda que reverterá na satisfação pessoal. Velhos(as) e jovens tidos como bem-sucedidos tornam-se veículos de extração e circulação de fluxos de informação das mídias eletrônicas e redes sociais que constituem a máquina social na atualidade. Assim, as modulações tidas como vitoriosas são construções das máquinas de informática, que roubam um corpo e devolvem uma virtualidade (imaterial).

Afetos e signos circulam sem o suporte de um sujeito individuado. A velhice e o envelhecimento vencedores são fabricados por um cruzamento de dados sem a referência a um sujeito específico. E esses servem para fazer funcionar a máquina social de méritos e deméritos que justificam investimentos e contensões.

Exemplificando as verdades enunciadas: afirma-se o aumento da população de velhos(as) e, em seguida, deriva daí o impacto sobre o sistema da previdência. A solução para essa conexão causal resulta numa gama de propostas que vão do aumento da idade para a aposentadoria às alternativas de previdência privada, estimulando-se um mercado de assessorias para orientação das pessoas sobre como gerir uma poupança e planejar seu futuro. E mais, difunde-se a positividade das velhices produtivas ou ativas que não se aposentam. 
$\mathrm{Na}$ esteira dessa certificação, as ciências da saúde afirmam que ser inativo é estar exposto aos riscos de contrair inúmeras doenças, relacionando a saúde às existências produtivas. Tudo isso alimenta o mercado de empreendedores e voluntários.

O governo das condutas, segundo Foucault (2008a, p. 242) produz como efeitos um tipo de sujeito e um modo de subjetivação.

Primeiro, uma individuação por sujeição ou por se deixar conduzir por regras de outrem, configurando uma rede contínua de obediências; segundo, tornar-se alvo de uma identificação analítica por meio da circulação de prêmios e recompensas pela maneira como se comporta sob o efeito de uma conduta; terceiro, uma subjetivação por um movimento duplo de extração de uma verdade interior que lhe é imposta.

Com base em Deleuze e Guattari (1997, pp. 156-159), destaco na análise do funcionamento do capitalismo atual a combinação de um duplo regime de assujeitamento: a sujeição social centrada no sujeito individual - que no neoliberalismo configura-se no capital humano ou empresário de si - e a servidão desindividualizada em banco de dados e segmentos flexíveis que produzem o conjunto da máquina social. À sujeição social que sujeita indivíduos se acopla uma servidão maquínica — "divíduos"- máquina. Como sujeitos, somos individualizados e sujeitados ao governo das condutas (que nos atribui papéis sociais e uma sujeição social), mas somos servos dos dispositivos tecnológicos da informática e demais meios de comunicação como usuários-produtores (servidão maquínica). Na servidão maquínica realizam-se trocas de informações, ou melhor, a circulação de fluxos informacionais se dá por componentes humanos e não-humanos. ${ }^{6}$

Retomo o conceito de governo, cunhado por Foucault (2008a, 2008b), como aquele que se encarrega de conduzir a conduta dos homens. Essa modalidade de exercício de governo é herdeira das tecnologias do pastorado cristão, "um tipo de poder bem específico que se dá como objeto a conduta dos homens - quero dizer, por instrumento os métodos que permitem conduzi-los e por alvo a maneira como eles se conduzem como eles se comportam (...). O pastorado é um poder que tem de fato por objetivo a conduta dos homens" (Foucault, 2008a, p. 256).

\footnotetext{
${ }^{6}$ Lazzarato (2014, pp. 27-51), retomando do pensamento de Deleuze e Guattari, afirma o duplo regime ao qual cada um está submetido no capitalismo: "por um lado, somos servos dos dispositivos maquínicos da empresa, das comunicações, do Estado de bem-estar-social e das finanças; e por outro, somos assujeitados à estratificação de poder que nos atribui papéis e funções produtivas e sociais, como usuários, produtores, telespectadores e assim por diante" (Lazzarato, 2014, p. 38).
} 
Os movimentos de resistência, insubmissões e revoltas de conduta "têm como objetivos, outra conduta, isto é: querer ser conduzido de outro modo, por outros condutores, outros pastores, para outros objetivos, e para outras formas de salvação, por meios de outros procedimentos e de outros métodos" (Foucault, 2008a, pp. 256-257). Há, portanto, para Foucault, "uma correlação imediata entre conduta e contraconduta" (Foucault, 2008a, p. 258).

Em face dos alvos das revoltas de conduta ou contracondutas, seus objetivos nunca são autônomos (Foucault, 2008a, p, 260). Essas resistências de conduta e conflitos em torno do problema da conduta deixam claras as seguintes questões: "Por quem aceitamos ser conduzidos? Como queremos ser conduzidos? Em direção ao que queremos ser conduzidos?” (Foucault, 2008a, p. 260).

Desde o século XVIII, “muitas das funções pastorais foram retomadas no exercício da governamentalidade, na medida em que o governo pôs-se a também querer se encarregar da conduta dos homens, a querer conduzi-los" (Foucault, 2008a, p. 260). A partir desse momento, surgem também as revoltas e conflitos de conduta, não em relação às instituições religiosas, mas em relação às instituições políticas (Foucault, 2008a, p. 261). Esses revoltosos almejavam ser conduzidos por outros homens e de outra maneira.

“O pastorado, em suas formas modernas, estendeu-se em grande parte através do saber, das instituições e das práticas médicas. Pode-se dizer que a medicina foi uma das grandes potências hereditárias do pastorado" (Foucault, 2008a, p. 263). Nessa medida também suscitou uma série de revoltas de conduta, tais como: a recusa de certos tratamentos e medicações, o uso de tratamentos alternativos sem aval da ciência médica, etc. Para Foucault, essas resistências são uma modalidade de contraconduta.

A maneira como se articulam sujeições e produção de assujeitamentos das velhices é a sua patologização. Aliás, essa patologização não é privilégio somente dos velhos(as), mas, desde o século XIX, estende-se à vida. Na perspectiva da economia política da medicina, o aumento da população, particularmente da população de velhos, aparece como alto custo econômico, demandando os serviços médicos, hospitalares e laboratoriais. Além disso, o aumento da longevidade tem sido apontado como a causa da crise da previdência social.

De fato, a medicalização da vida amplia as sujeições e assujeitamentos. A saúde se converteu num objeto de intervenção médica. Essa intervenção estende-se a um campo muito amplo da existência individual ou coletiva. "A medicina se impõe aos indivíduos, doentes ou não, como ato de autoridade" (Foucault, 2010, p. 180). 
E, por que não dizer, de modo autoritário. Hoje, a medicina não se limita, como outrora, a fornecer à sociedade indivíduos aptos para atuarem como força de trabalho, ou seja, como instrumento de manutenção e reprodução da força de trabalho. A medicina, hoje, é produtora direta de riqueza, na medida em que a saúde constitui objeto de desejo para uns e de lucro para outros (Foucault, 2010, p. 188).

Segundo o mesmo autor, "O corpo humano se introduziu duas vezes no mercado: a primeira, através do assalariado, quando o homem vendeu sua força de trabalho, e a segunda, por intermédio da saúde".

O corpo humano entra no mercado econômico enquanto suscetível às doenças e à saúde, ao bem-estar, ao mal-estar, à alegria ou ao sofrimento etc. O corpo humano entra no mercado do consumo de medicamentos, consultas médicas, exames laboratoriais, internações hospitalares, planos e seguros de saúde (Foucault, 2010, p. 188). A vida tornouse uma coisa cara, muito custosa. Endivida-se com a promessa de viver mais e melhor. Estamos todos endividados, afirma Deleuze (1992), acerca da sociedade de controle.

Em relação ao funcionamento do capitalismo atual, o conceito de pastorado como governo das condutas de sujeitos individualizados, conforme exposto anteriormente, com base em Foucault, deverá ser acrescido, segundo Lazzarato (2014, p. 38), da nova modalidade de governamento de "dividuais", gerenciada por fluxos, redes e máquinas, como tecnologias de modelização e modulação, intervindo na sensibilidade, na percepção, na linguagem e no conhecimento. As resistências, portanto, deverão dirigir-se contra a servidão e a sujeição.

\section{A ética como estética da existência: uma anticonduta}

Seguindo as sugestões de Edson Passetti (2013) e Acácio Augusto (2013, p. 157) adoto o termo anticonduta para caracterizar uma ética como estética da existência que não se inscreve na relação conduta-contraconduta. Não se trata, portanto, de uma nova maneira de ser conduzido ou governado, mas de um modo de vida, de uma ética como estética da existência que rompe com as relações de poder (estatal ou não estatal) para dar lugar a uma vida da potência ou vida artista.

\footnotetext{
${ }^{7}$ Em sua tese de doutorado, sob a orientação de Passetti, Acácio Augusto refere-se a uma atitude libertária como aquela que "rompe com as conduções e afirma uma anticonduta, o que não se espera, o que não está justificado nem teórica nem moralmente, emergência do insuportável" (2013, p. 157).
} 
É nesse sentido que se situa um envelhecimento artista. Longe, portanto, de qualquer modelo que possa compor-se em Programa de governo das condutas.

Retomo de Deleuze (1992) a referência a um modo de subjetivação que não envolve uma relação externa de forças com outras forças, mas uma "dobra" da força sobre si mesma, constituindo modos de existência ou a invenção de novas possibilidades de vida, e também de morte (p. 116), que não se curvam às regras do poder, mas inventam "regras facultativas que produzem uma existência como obra de arte" (p. 120).

Diferentemente da moral, que se guia por valores transcendentes do que é certo e do que é errado, do que se deve ou não fazer, a ética é um conjunto de regras facultativas que avalia o que fazemos e o que dizemos, em função do modo de existência implicado (Ibid., p. 125). A estética da existência é uma maneira de viver que não está ligada a um código de comportamento, mas depende de certas formas. As artes de existência, segundo enunciado de Foucault (1998, p. 15) aludindo aos filósofos gregos da Antiguidade, "são práticas refletidas e voluntárias através das quais os homens não somente se fixam regras de conduta, como também procuram se transformar, modificar-se em seu ser singular e fazer de sua vida uma obra que seja portadora de certos valores estéticos e responda a certos critérios de estilo". São essas artes ou "técnicas de si" que perderam sua autonomia com o poder pastoral cristão e seus herdeiros, as práticas educativas médicas ou psicológicas (Foucault, 1998, p. 15).

Destaco o problema da potência da velhice na atualidade. Algumas questões se colocam: como se livrar dos governos que se apropriam do corpo e da vida de cada um e da população dos velhos para dirigir a sua conduta? Hoje, dos velhos(as) e jovens se exige obediência à condução das condutas. Diante isso, o problema que se põe, na atualidade, em relação à velhice, é o de uma anticonduta ética como estética da existência.

Meu interesse pela velhice e o envelhecimento se deu, primeiro, na experimentação desse processo no meu próprio corpo e, segundo, pelo mal-estar em relação ao tratamento dado às velhices na atualidade. Que sujeito se produz para o corpo que envelhece? Como já dito anteriormente, trata-se de uma sujeição e um assujeitamento aos modelos de corpo e de vida considerados saudáveis.

Escrevemos para experimentar a diferença, ou seja, tornarmo-nos diferentes de nós mesmos. Há um duplo comprometimento na escrita que não se aparta da vida: uma dessubjetivação e a produção de novas subjetividades insubmissas. A urgência desses escritos é a busca de novos possíveis: arremeter-se para o fora dos dispositivos das relações de poder e estratificação de saber. 
$\mathrm{E}$, àqueles que esperam desse texto uma alternativa ou proposta de ação política para as críticas empreendidas, respondo com uma questão-problema, posta por Deleuze (citado em Lapoujade, 2015, pp. 263-264): Como se tornar capaz de ação? Encontrar nas forças do tempo um novo tempo e espaço que resista aos modos de subjetivação das velhices existentes - nota-se, de sujeição e servidão —, para lançar-se ao clamor de uma velhice que falta ${ }^{8}$. É com essa perspectiva que lanço a ideia de um envelhecimento artista.

Retomando o pensamento de Foucault (2008a, p. 266) exposto anteriormente sobre a relação conduta-contraconduta; as resistências ao governo das condutas surgem no interior de uma relação com objetivos diferentes. Por um lado, ocorrem revoltas ou contracondutas que se contrapõem aos procedimentos com os quais são conduzidas as condutas, almejam sua modificação, aspiram por participação nas tomadas de decisões de governo. Por outro lado, as ações de contracondutas não se colocam de modo autônomo em relação às condutas, mas aspiram outra direção, ou modo de ser conduzido e de conduzir.

As resistências se dão no interior das relações de poder. Pois onde existe poder existe resistência, afirma Foucault (2005, p. 91). Contudo, resistir não se reduz à reação ou mudança dos procedimentos de conduzir ou ser conduzido. Resistir pode ser curto-circuitar o próprio funcionamento do mecanismo, colapsar uma relação de poder sem visar qualquer alternativa que se pretenda universal. Esvaziar sem ocupar. Lançar-se ao aberto do acontecimento em que circulam afetos e intensidades e o impensável no pensamento. Retomo a ideia inicial de uma resistência como anticonduta.

A ética como estética da existência na direção de uma anticonduta promove uma dupla resistência: à sujeição e à servidão. Assim, situa-se a estética da existência como um modo de vida nada tranquilizador, tampouco um receituário de saídas fáceis, nem a emissão de slogans consoladores.

\section{Vida outra, envelhecimento artista}

Em lugar do envelhecimento ativo por que não experimentarmos um envelhecimento artista? Como artistas, podemos lançar sobre nós um olhar perspectivo, tomarmos distância de nós mesmos para rirmos de nossas misérias, rabugices e mesquinharias.

\footnotetext{
${ }^{8}$ Aproprio-me, aqui, de uma ideia do filósofo Gilles Deleuze: um povo que falta. 
E mais, por meio dessa arte zombeteira, conquistar a liberdade em relação às coisas e seus ideais que nos imputam pesados papeis, promessas redentoras e de felicidades impossíveis. É com alegria que atravessamos a torrente dissolutora do devir da existência equilibrando sobre o fio que, com a ajuda dos amigos, vamos tecendo com nossas dores, doenças, prazeres e desprazeres, amores e decepções, sem medo de escorregar e cair, porque aprendemos a flutuar e a brincar. Ora, dirão aqueles defensores da seriedade da existência, - como viver com alegria diante de tanta miséria, morte e doença?! Ciente e atenta a tudo isso, selecionamos aquilo que está em nosso poder de combate; para isso é preciso, como diria Nietzsche (2012, p. 480), ser saudável o suficiente.

Não se combate a doença e a tristeza sem alegria e saúde. E os poderosos criam a miséria para fazer de nós dependentes de seu governo e de sua exploração. E quanto menos nós temos e recebemos mais temerosos nos tornamos de perdermos.

Em sua autobiografia, Ecce homo: como alguém se torna o que é, Nietzsche expõe - como o próprio título sugere - o seu percurso de produção de si como obra de arte. Afirma o filósofo, "tomei a mim mesmo em mãos (...), fiz da minha vontade de saúde, de vida, a minha filosofia..." (Nietzsche, 1995, p. 25). A despeito da doença e da morte, e em relação com elas, a saúde se adquire em cada momento, e é necessário que assim seja. Nada nos é dado em definitivo... O verbo tornar-se exprime o devir. O sujeito é um produzir-se em relação consigo e com o mundo. Trata-se de uma subjetividade corporal atravessada por relações de forças múltiplas que se hierarquizam em perspectivas variadas. É preciso muita arte! “E uma arte para artistas, só para artistas!” (Nietzsche, 2001, Introdução, § 4, p. 15).

Tudo muda quando se direciona o foco para o artista. A força da arte passa a residir no seu processo de produção e menos no produto enquanto objeto separado. E, se eles não se separam, isto não significa que são os mesmos, pois o sujeito não é um ente dado que se transforma, mas ele se produz no incomensurável jogo de forças do devir. Temos aí uma primeira formulação de uma subjetividade. A arte do artista aproxima-se da ideia de finitude e de produção do ser no mundo, um mundo que nunca cessou de perecer, por isso, "um construir e destruir, sem nenhuma prestação de contas de ordem moral" (Nietzsche, 1974, § 7, p. 44).

O deslocamento da arte do objeto artístico que serve de fruição ao espectador para o artista permite a este um experimento, nada inocente, mas, sim, com elevada periculosidade. 
Agamben (2012, p. 24) refere-se às experimentações de Hölderlin no limiar da loucura; ao risco de viver mencionado por Van Gogh; a "uma experiência levada até o extremo", de acordo com Rilke. Por fim, para Rimbaud, uma promessa de felicidade trazida pela poesia desmorona e faz o poeta mergulhar no silêncio.

Assim, é sob a perspectiva da vida que, na sua imanência e criação liberta dos códigos de uma moral transcendente, a existência se faz sentir, pensar e agir, produzindo um "si". A ética toma a vida como referência, e mais, é a vida que avalia. E a vida, como vontade de potência, segundo Nietzsche, não quer se preservar, mas fazer-se como puro devir. Assim a ética atravessada pela vida só poderá converter-se em regras facultativas construídas no tempo certo - o momento ou instante efetivamente vivido denominado de tempo kairós.

E por que se desejaria prolongar a existência? Certamente não para atingir uma idade avançada, mas para experimentar algo forte demais, no encontro com as potências da vida, a despeito das doenças que acometem o vivente, ou com elas mesmas, a fim de alcançar a grande saúde, de acordo com o conceito nietzschiano, "aquela que não basta ter, a que se adquire, que é necessário adquirir, constantemente, por ser sacrificada sem cessar, por ser necessário sacrificá-la sem cessar!...” (Nietzsche, 2001, §282, p. 283).

Deleuze e Guattari (1992, p. 9) afirmam:

Há casos em que a velhice dá, não uma eterna juventude, mas ao contrário, uma soberana liberdade, uma necessidade pura em que se desfruta de um momento de graça entre a vida e a morte, em que todas as peças da máquina se combinam para enviar ao porvir um dardo que atravesse as eras...

Como vimos, um modo de envelhecimento artista ou vida outra, afronta às instâncias de gestão da vida segundo uma modulação da subjetividade de acordo com valores da máquina social. O que se retém é uma atitude de resistência, de afronta à sujeição e à servidão. Arte e vida não se distinguem, mas se articulam para fender a cultura existente.

E por que se quer prolongar a existência? O filósofo Gilles Deleuze, na companhia de seu amigo Guattari, afirma: para viver algo grande demais que "lance um dardo que atravesse as eras" (1992, p. 9). E, a quem espera apanhá-lo, é preciso alertar que se trata de algo que não é pacificador, mas que segue a linha de fuga da bruxa... e nos torna diferentes do que somos. 
E mais, concordo com Deleuze e Guattari $(1992,140)$ ao afirmarem que a adesão aos valores da época atual é estabelecer compromissos vergonhosos com as possibilidades de vida que nos são oferecidas.

Com essa referência, encerro abrindo uma brecha para a velhice como uma obra de arte e um envelhecimento artista em que a insistência em viver passa ao largo da dita "qualidade de vida" que nos é oferecida, para roçar a vida como intensidade e, assim, experimentar algo grande demais que promova um corte, criando uma cesura no curso do tempo cronológico (ou curso da vida). E, com a coragem dos que estão dispostos a correr o risco de viver, irromper numa outra temporalidade e encontrar as potências do tempo e a intensidade do devir, pois o estar entre a vida e a morte não é somente ao pé da letra estar próximo da morte, mas, sim, um entretempo onde tudo pode acontecer.

\section{Referências}

Agamben, G. (2012). O homem sem conteúdo. Claudio Oliveira, Trad. Belo Horizonte, MG: Autêntica.

Augusto, A. (2013). Política e antipolítica: anarquia contemporânea, revolta e cultura libertária. Tese de doutorado. São Paulo: PUC-SP: Programa de Estudos Pós-Graduados em Ciências Sociais.

Deleuze, G. (1992). Conversações. Peter Pál Pelbart, Trad. Rio de Janeiro, RJ: Editora 34.

. Diferença e repetição. (2006). Luiz Orlandi, \& Roberto Machado, Trads. (2 $2^{\mathrm{a}}$ ed.). Rio de Janeiro, RJ: Graal.

Deleuze, G., \& Guattari, F. (1992a). O que é a filosofia. Bento Prado Jr. e Alberto Alonso Muñoz, Trad. Rio de Janeiro, RJ: Editora 34.

Aparelho de captura. (1997). Janice Caiafa, Trad. In: Mil Platôs, capitalismo e esquizofrenia. (vol. 5). São Paulo, SP: Editora 34.

Foucault, M. (1998). História da sexualidade - o uso dos prazeres. (vol. 2). Maria Thereza C. Albuquerque, Trad. ( $8^{\mathrm{a}}$ ed.). Rio de Janeiro, RJ: Graal.

(2004). Hermenêutica do sujeito. Márcio Alves da Fonseca e Salma Tannus Muchail, Trads. São Paulo, SP: Martins Fontes.

. (2005). História da sexualidade - a vontade de saber. (vol. 1). Maria Thereza C.

Albuquerque e J. A. Guilhon Albuquerque, Trads. (16 ed.). Rio de Janeiro, RJ: Graal.

(2008a). Segurança, território e população. Eduardo Brandão, Trad. São Paulo, SP: Martins Fontes.

(2008b). Nascimento da Biopolítica. Eduardo Brandão, Trad.. São Paulo, SP:

Martins Fontes.

(2010). Crise da medicina e da antimedicina. Heliana Conde, Trad. In: Revista Verve, 18, pp. 167-194. São Paulo, SP: Nu-Sol/PUC-SP. 
(2014). Do governo dos vivos. In: Da Motta, Manoel de Barros (Org.). Ditos $e$ Escritos IX. Abner Chiquieri, Trad. Rio de Janeiro, RJ: Gen/Forense Universitária.

Gros, F. (2004a). Situação do curso. Foucault, M. A hermenêutica do sujeito. Marcio A. da Fonseca e Salma Tannus Muchail, Trad. São Paulo, SP: Martins Fontes.

(2004b). A parrhesia em Foucault (1982-1984). In: Gros, F. (Org.). Foucault: A coragem da verdade. Marcos Martiolino, Trad. São Paulo, SP: Parábola Editorial, 2004b.

Lapoujade, D. (2015). Deleuze, os movimentos aberrantes. Laymert Garcia dos Santos, Trad.. São Paulo, SP: N-1 edições.

Lazzarato, M. (2014). Signos, Máquinas, Subjetividades. Paulo Domenech Oneto, Trad. São Paulo, SP: Edições Sesc/ n-1 edições.

Oliveira, S. (2012). Política e resiliência: apaziguamentos distendidos. In: Revista Ecopolítica, 4, 105-129. São Paulo, SP: Nu-Sol/PUC-SP, n. ${ }^{\circ}$ 4. Recuperado em 28 novembro, 2016, de: http://revistas.pucsp.br/index.php/ecopolitica/article/view/13067.

OMS. (2015). Organização Mundial de Saúde. Relatório Mundial de Envelhecimento e Saúde (Resumo). Recuperado em 28 novembro, 2016, de: http://sbgg.org.br/wpcontent/uploads/2015/10/OMS-ENVELHECIMENTO-2015-port.pdf.

OPAS, OMS. (2005). Envelhecimento ativo: uma política de saúde. Suzana Gontijo, Trad. Brasília, DF: Organização Pan-Americana da Saúde / Organização Mundial de Saúde, 2005. Recuperado em 28 novembro, 2016, de: https://www.nescon.medicina.ufmg.br/biblioteca/imagem/4478.pdf

Nietzsche, F. (1974). A filosofia na época trágica dos gregos. In: Obras Escolhidas. Os Pensadores. Rubens Rodrigues Torres, Trad. São Paulo, SP: Abril Cultural.

. (1995). Ecce Homo: como alguém se torna o que é. Paulo César de Souza, Trad. São Paulo, SP: Companhia das Letras.

. (2001). A Gaia Ciência. Paulo César de Souza, Trad.. São Paulo, SP: Companhia das Letras, 2001.

. (2012). Fragmentos Póstumos- 1887-1889. Marco Antônio Casanova, Trad. Rio de Janeiro, RJ: Forense Universitária.

Passetti, E. (2013). Transformações da biopolítica e a emergência da ecopolítica. In: Revista Ecopolítica, 5, pp. 02-37. São Paulo, SP: Nu-Sol / PUC-SP. Recuperado em 28 novembro, 2016, de: http://revistas.pucsp.br/index.php/ecopolitica/article/view/15120/11292.

Recebido em 10/03/2017

Aceito em 30/03/2017

Silvana Tótora - Professora do Departamento de Política, Faculdade de Ciências Sociais (FCS/PUC-SP) e dos Programas de Estudos Pós-Graduados em Gerontologia e em Ciências Sociais, PUC-SP.

E-mail: silvanatótora@gmail.com 